\title{
Discussion on the Validity of Logistics Management
}

\author{
Liu Lijuan \\ Yunnan Vocational Institute of Energy Technolgy, Yunnan Qujing, China, 655000
}

Keywords: modern enterprise; logistics management; innovation

\begin{abstract}
With the rapid development of China's economy and the accelerating pace of economic globalization, the scale of commodity trade has expanded rapidly, and the breadth and depth of material space movement have also expanded. As a result, the efficiency of logistics activities, the ability to quickly respond to logistics, and information The degree of development has put forward higher requirements. The purpose of implementing logistics management is to realize the established level of customer service under the lowest possible total cost, that is, to seek a dynamic balance between service advantages and cost advantages, and thereby create a strategic advantage for the enterprise in competition.
\end{abstract}

\section{Introduction}

With the accelerating pace of economic globalization and the rapid development of China's economy, the scale of global merchandise trade has gradually expanded, and the depth and breadth of material space movement have also expanded. As a result, the rapid response capabilities of logistics, logistics information, logistics activities Efficiency has put forward higher requirements. At the same time, logistics needs are highly demanding, personalized, and diversified. Logistics service companies must continuously improve and optimize their business models, improve logistics services, and develop new types of logistics services in a targeted manner to meet the changes in the logistics market and improve the company's Competitiveness. How do companies keep their core competitiveness? Why are some companies short-lived, some are downhill, and some are still struggling? Throughout China and foreign famous enterprises, modern logistics management is extremely important, especially supply chain management for raw material suppliers, industrial companies, commercial enterprises, retail industries, and other logistics supply chain in the aspects of logistics information, resource allocation, logistics processes, cost control, etc. Control, innovation and adjustment[1].

\section{Analysis of Concept and Features of Modern Business Logistics}

With the progress and development of the times, the concept of corporate logistics has also been continuously developed and improved. Not only has the scope of functions of logistics activities been continuously expanded, but the connotation of logistics has also become more and more extensive. Modern logistics shows the following characteristics: First, modern logistics is a system-integrated collaborative logistics. From the inside of the company, it is the integrated coordination and integration of logistics operations processes such as information, transportation, 
material supply, handling, inventory management, packaging, warehousing, physical distribution, etc. From the perspective of supply chain strategic management, modern logistics management Directs the logistics operations across the organization and realizes the coordination of the supply chain. Enterprise logistics not only needs to consider its own customers, but also consider its own suppliers; not only consider the customer's customers, but also take into account the supplier's suppliers; not only to reduce the cost of a logistics operation, but more importantly To work to reduce the total cost of the entire supply chain operation. Second, modern logistics is the choice of logistics strategy. In logistics, although it is very important in terms of costs, the importance of modern logistics not only saves costs, but also the most important thing is to balance the cost with the long-term benefits of the company and the level of customer service. How to choose a logistics strategy to gain a competitive advantage. Third, modern logistics is customer service logistics, customer service is the driving force of logistics innovation. The core of today's business management concepts has shifted from product manufacturing to marketing and customer service. In response to this, the company's logistics actions also extend to the upstream and downstream processes of the company's production process on the basis of the organization of product production, especially the addition of products. A series of activities such as sales and after-sales services, modern logistics will be more value-oriented to corporate customer service, emphasizing logistics-driven customer orientation, and customer-driven logistics[2].

\section{Modern logistics management innovation is a means to improve corporate performance}

As China becomes a world factory and the Chinese domestic market continues to develop, the cost advantage or value advantage of companies will be the goals that companies must achieve to survive and grow. The competitive advantage of an enterprise can be obtained through such means as management innovation, technological innovation, and market innovation. Along the axis of value advantages, logistics management innovation can shorten lead time, increase reliability, quickly respond, and provide personalized services. First, the center of modern logistics management innovation lies in the innovation of core business processes of existing enterprises. Since industrialization, the company's core business processes have been divided into separate steps by different departments and people. These divided business processes have many mistakes, many steps, long cycle, and slow response. These are all competitive killers. Innovation is to shorten the cycle, reduce steps, and speed up. With fewer steps, the product backlog and inventory will be reduced accordingly, resulting in higher production efficiency. Modern logistics management focuses on the reasonable control of the total cost of the entire logistics system and the management of the entire supply chain logistics. To enhance the competitiveness of the entire enterprise, the company's focus cannot be solely on technological innovation and the optimization of production lines. To make production profitable and to reduce the cost of space is limited, we must start with logistics management, through superior logistics efficiency, create cost advantages for enterprises, improve corporate profits, and increase market share. Second, modern logistics management can optimize the value creation process of the supply chain and increase the core competitiveness of the company. Competitive advantage comes from the fact that companies can create higher value than other competing companies. This value is manifested by the difference in cost. For customers, the value can be unique or low price. Value advantage is the ability to differentiate value from competitors. A well-managed logistics management company can become an attractive supplier and ideal business partner if it is ahead of the industry average in terms of availability, delivery timeliness, and delivery consistency. A company with excellent logistics capabilities can gain competitive advantage by providing customers with quality services. Efficient logistics management determines the level of the company's profits, but also determines the company's core 
competitiveness. With the development of information technology and the widespread use of the Internet, logistics management, which has always played an auxiliary role, has played an increasingly important role in building the core competitiveness of enterprises[3].

\section{Ways to Improve the Efficiency of Enterprise Logistics Management}

\subsection{Establishing a logistics information system and providing a logistics management platform}

Modern management is mainly reflected in the development and application of logistics information. There are three prerequisites for logistics management informationization: (1) A complete set of logistics information management system, which provides electronic management for logistics operations; (2) A method that can quickly, easily, safely, and reliably exchange data. Exchange platform. (3) To provide users with personalized logistics information services. To this end, companies should increase investment and establish computer-supported logistics information systems[4]. The logistics management structure is as follows.

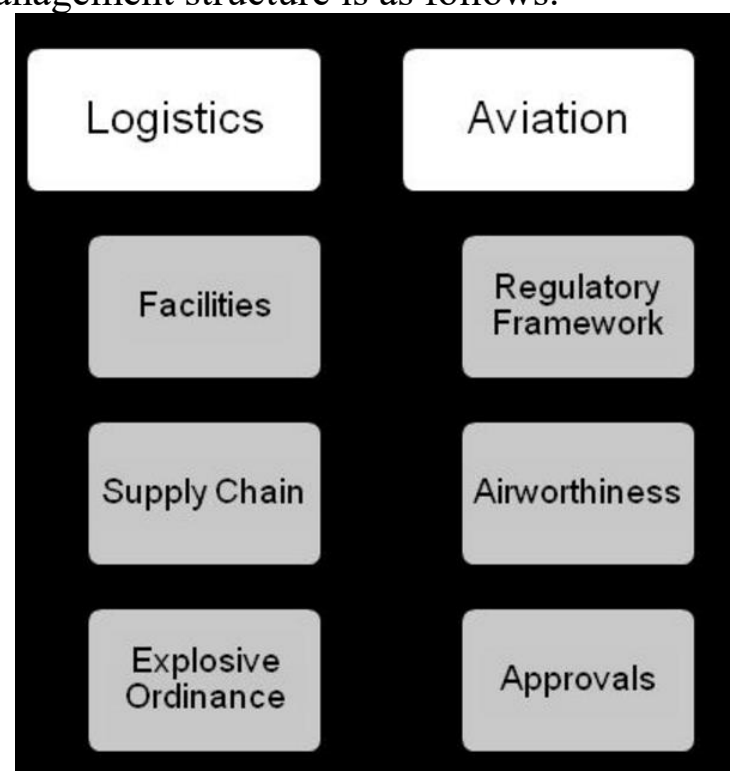

Fig.1 Logistics management structure

\subsection{Establishing an Industry Logistics Service Model}

The industry logistics service model is based on the use of modern technology and specialized management methods. Based on the rich experience of the target industry and the deep understanding of the needs of customers, it provides a full or partial professional logistics service within a certain industry field. mode. The main feature of this business model is that the object of logistics service is divided into several specific industry fields, and then this industry is studied in-depth and detailed, to master the logistics operation characteristics of the industry, and provide professional services with special features. The industry logistics service model integrates the company's business philosophy, business, management, talent, capital, and other advantages, and is a concentrated expression of the company's core competitiveness and competitive advantage. The trend of logistics data is as follows. 


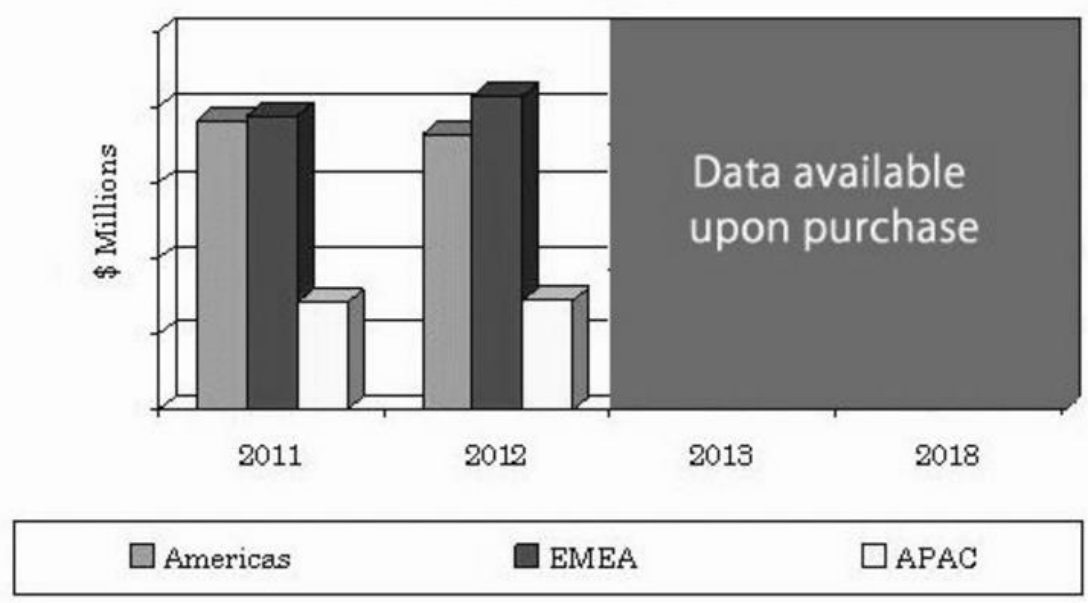

Fig.2 Trend of logistics data

\subsection{Continuously improve the logistics process and increase new services}

First of all, to achieve inventory rationalization. The level of inventory affects the level of logistics costs to a large extent. Enterprises should reduce inventory levels as much as possible while ensuring supply, and strive to achieve "zero inventory." If there is a lack of optimal control, long transportation routes, too small transport volumes, or transportation solutions with high transportation costs, it will cause a linear rise in transportation costs. Therefore, reasonable transportation batches should be established, economical transportation routes and transportation options should be selected so as to save transportation costs. Again, increase the content of logistics services, so that customers "involved in" logistics. Finally, to establish a scientific, rational, and optimized distribution network and distribution center, whether the product can reach the destination quickly through the supply chain depends on the soundness of the logistics and distribution network.

\section{Summary}

Judging from the experience of outstanding foreign companies, profits and logistics management have become the norm, but the development of the domestic modern logistics industry started late, the foundation is poor, and technology and ideas have to be improved. Whether logistics management can bring lucrative returns to domestic enterprises requires industry. Work together. With the development of the western and mid-west and the development of e-commerce, enterprises should seize the opportunity to adjust the market position, identify the market position, introduce advanced logistics technology from abroad, develop products suitable for the needs of China's local market, and improve the integration of enterprises. Competitiveness and improve the overall level of enterprise-wide logistics management. In the near future, corporate logistics management will surely become a true "third source of profits."

\section{References}

[1] Matjaž Knez, Peter Bajor. The Value of "Vehicle to Grid" Integration into Warehouse Logistics Management - Case of Slovenian Retailer[J]. Organizacija,2011,44(5).

[2] Justyna Dobroszek, Anna Szychta. Indicators as an Instrument of Measurement in Management Accounting in Logistics Enterprises in Poland[J]. Management and Business Administration, 2016,23(4).

[3] Sirpa Multaharju, Katrina Lintukangas, Jukka Hallikas, Anni-Kaisa Kähkönen. Sustainability-related risk 
management in buying logistics services[J]. The International Journal of Logistics Management,2017,28(4).

[4] Mengru Tu. An exploratory study of Internet of Things (IoT) adoption intention in logistics and supply chain management[J]. The International Journal of Logistics Management,2018,29(1). 